\title{
A CONSTRUÇÃO DE UMA NAÇÃO: ENTRE A CONSERVAÇÃO E A MUDANÇA NO SÉCULO XX BRASILEIRO
}

\author{
LA CONSTRUCCIÓN DE UMA NACIÓN: ENTRE LA CONSERVACIÓN Y EL \\ CAMBIO EN EL SIGLO XX BRASILEÑO
}

\author{
BUILDING A NATION: BETWEEN CONSERVATION AND CHANGE IN BRAZIL'S \\ XX CENTURY
}

Laura Gabrieli Pereira da SILVA ${ }^{1}$ Fabrício Henrique de OLIVEIRA ${ }^{2}$

RESUMO: Este artigo visa estudar a contradição entre as teorias racialistas do final do século XIX e o anseio da década de 30 em construir um Estado-Nação moderno e com o desenvolvimento capitalista autônomo. Em outras palavras, o presente trabalho analisará as dificuldades de pensar o Estado moderno em um país que havia sido impregnado por teorias racialistas que não só condenavam a possibilidade do desenvolvimento como também versavam especificamente sobre a população brasileira. A fim de elucidar essa reflexão, recorremos à literatura, em especial ao livro O Cortiço (1890) de Aluísio Azevedo, no qual a construção de duas personagens negras demonstra como as teorias racialistas se difundiram em vários campos do conhecimento: Bertoleza, mulher negra escravizada, e Rita Baiana, estereótipo da mulata sensual. Recorremos também a autores como Raimundo Nina Rodrigues, Gilberto Freyre, Florestan Fernandes e Carolina de Jesus.

PALAVRAS-CHAVE: Teorias racialistas. Estado-nação. Literatura. Modernização. Miscigenação.

RESUMEN: Este artículo apunta a estudiar la contradicción entre las teorías racialistas de finales del siglo XIX y el anhelo de la década del 30 en construir un Estado-Nación moderno y con el desarrollo capitalista autónomo. En otras palabras, el presente trabajo analizará las dificultades de pensar el Estado moderno en un país que había sido impregnado por teorías racialistas que no sólo condenaban la posibilidad del desarrollo sino que también versaban específicamente sobre la población brasileña. En el caso de la construcción de dos personajes negros, la construcción de dos personajes negros demuestra cómo las teorías racialistas se difundieron en varios campos del conocimiento: Bertoleza, mujer negra esclavizada, a la luz de la literatura, en especial al libro O Cortiço (1890) de Aluísio Azevedo, y Rita Baiana, estereotipo de la mulata sensual. También recurrimos a autores como Raimundo Nina Rodrigues, Gilberto Freyre, Florestan Fernandes y Carolina de Jesús.

PALABRAS CLAVE: Teorías racialistas. Estado-nación. Literatura. Modernización. Miscigenación.

${ }^{1}$ Universidade Estadual Paulista (UNESP), Araraquara - SP - Brasil. Graduanda em Ciências Sociais. ORCID: <http://orcid.org/0000-0002-0784-8990>.E-mail: laura.gabrieli@fclar.unesp.br.

${ }^{2}$ Universidade Estadual Paulista (UNESP), Araraquara - SP - Brasil. Graduando em Ciências Sociais. ORCID: <https://orcid.org/0000-0002-1947-0761>. E-mail: 10faboliveira@ gmail.com. 
ABSTRACT: ABSTRACT: This article aims to study the contradiction between the racialist theories of the late nineteenth century and the thirties of the 1930s to build a modern nation state and autonomous capitalist development. In other words, the present work will analyze the difficulties of thinking about the modern state in a country that had been impregnated by racialist theories that not only condemned the possibility of development but also related specifically to the Brazilian population. In order to elucidate this reflection, we turn to literature, especially Aluísio Azevedo's book $\boldsymbol{O}$ Cortiço (1890), where the construction of two black characters demonstrates how racialist theories spread in various fields of knowledge: Bertoleza, a black enslaved woman, and Rita Baiana, stereotype of the sensual mulatto. We also appeal to authors like Raimundo Nina Rodrigues, Gilberto Freyre, Florestan Fernandes and Carolina de Jesus.

KEYWORDS: Racialist theories. Nation-state. Literature. Modernization. Miscegenation.

\section{Introdução}

Os anos de 1930 se constituíram como um período fundamental para a compreensão do século XX brasileiro. Não obstante ao seu compromisso de romper com o antigo sistema oligárquico agroexportador, já esgotado, e engendrado com a implementação da República em 1889, a década de trinta inaugura um momento decisivo para a afirmação de um projeto de desenvolvimento capitalista autônomo. Contendo em si a perspectiva de atualização da modernidade prometida pela primeira república (NOGUEIRA, 1988), os anos 30 surgem como marco histórico em razão da constituição de um Estado nacional, cujo impulso modernizador se verificará, sobretudo, em projetar a unificação cultural dessa sociedade.

Todavia, no âmbito da cultura existiam contrariedades em relação a essa pretensão de unicidade nacional, expostas pelo debate intelectual, ao fim do século XIX, sobre o destino do país a partir da temática da mestiçagem. Segundo compreensão corrente, o contato sexual entre grupos étnicos distintos estava posto como um árduo problema, pois na visão de autores da época, a mestiçagem implicava esterilidade biológica e cultural, sendo esse um elemento que inviabilizaria o desenvolvimento do país, já que impediria o completo domínio da raça branca e o consequente ingresso do país aos valores ocidentais de civilização.

\section{As teorias racialistas e o futuro do Brasil}

Silvio Romero, Euclides da Cunha e Raimundo Nina Rodrigues são considerados, por motivos e contribuições diversas, precursores das Ciências Sociais no Brasil ao terem se empenhado em estudar e compreender as bases da sociedade brasileira (CANDIDO, 2000). No 
que diz respeito aos estudos dos grupos afro-brasileiros, Antônio Cândido destaca fundamentalmente o papel de Nina Rodrigues, juntamente com Artur Ramos, em estabelecer uma tradição que estimula pesquisas inicialmente colocadas à margem do escopo da Sociologia, como por exemplo, na Psicologia e Antropologia.

Em particular, a produção intelectual de Nina Rodrigues insere-se no contexto antropológico do cenário científico do século XIX. Nesse sentido, Schwarcz (2008) ressalta como o paradigma desse período consiste na noção de evolução social, presente em interpretações de vertentes como o positivismo, evolucionismo e darwinismo, que partem de uma compreensão geral acerca da existência de uma associação entre caracteres genéticos, capacidade intelectual, comportamento e caráter moral. Segundo a autora, nesse momento também se inicia a criação conceitual e científica manifesta na terminologia de raças, “(...) inaugurando a ideia da existência de heranças físicas permanentes entre os vários grupos humanos" (SCHWARCZ, 2008, p. 43).

Assim, as três vertentes mencionadas anteriormente situam-se no núcleo teórico da defesa de modelos únicos e exclusivos tanto do ser humano em si quanto do desenvolvimento da humanidade, embasando-se na lógica da superioridade e inferioridade, de afirmação e negação, sobre a qual o lugar reservado aos indígenas, por exemplo, é o de passado fossilizado e exótico objeto de estudo. A partir da conexão entre a natureza e a cultura, técnicas de antropometria e frenologia foram amplamente empregadas e naturalizadas com fundamento no vínculo entre capacidade mental e tamanho cerebral. Tais estudos ocuparão papel fundamental nas teses de Antropologia Criminal com o par associativo de criminalidade e hereditariedade, defendido por Cesare Lombroso. Em meio à obra de Charles Darwin, por meio da publicação de “A Origem das Espécies”, em 1859, termos como hereditariedade, seleção natural e evolução são posteriormente transportados para diferentes redutos do conhecimento: fenômeno vislumbrável na formação da escola naturalista de literatura, por exemplo, e no paradigma do evolucionismo na Antropologia, expresso na perspectiva comparativa de desenvolvimento em autores como Morgan, Tylor e Frazer, onde a exclusividade e a restrição predominavam.

Com isso, almejavam captar o ritmo de crescimento sociocultural do homem, e, mediante as similaridades apresentadas, formular esquemas de ampla aplicabilidade que explicassem o desenrolar comum da história humana. Civilização e progresso, termos privilegiados da época, eram entendidos não enquanto conceitos específicos de uma determinada sociedade, mas como modelos universais (SCHWARCZ, 2008, p. 57).

A discussão intelectual dessa antropologia embasada em um modelo biológico de ser humano vincula-se à compreensão de que há, naturalmente, uma separação entre raças 
humanas, hierarquicamente classificadas e passíveis de valorização apenas em sua pureza, o que acarreta na condenação da figura do mestiço. Além disso, o aspecto biológico expresso na condição racial associa-se inadvertidamente com o comportamento cultural, esfera igualmente dotada de separação e hierarquia, em que o indivíduo carrega a herança negativa de seu grupo racial e aparta-se da condição de sujeito. Em 1855, Joseph Arthur, o Conde de Gobineau publicava a obra "Ensaio sobre a desigualdade das raças humanas", na qual afirmava categoricamente a superioridade do homem branco e o atraso inerente aos povos gerados pela miscigenação, caracterizados pela debilidade genética, cognitiva e moral. Acerca da questão da raça, Ki-Zerbo (2010) destaca que a leitura científica do termo passou por diversas etapas e por abordagens morfológicas e demográficas, cujas fraquezas teóricas derivaram na tendência a negar a existência das raças biológicas. Em realidade, "de acordo com Bentley Glass, não há mais de seis pares de genes pelos quais a raça branca difere da raça negra. Os brancos frequentemente diferem entre si num grande número de genes, o mesmo acontecendo com os negros" (KI-ZERBO, 2010, p. 288).

Contudo, os ideais e conceitos das teorias racialistas do século XIX, ainda que não mais se amparem tão explicitamente no âmbito biológico, penetraram nas práticas e mentalidades sociais. Assim como afirmado por Ki-Zerbo ao citar as declarações da UNESCO sobre o conceito de raça, "A raça é menos um fenômeno biológico do que um mito social” (KI-ZERBO, p. 289 apud UNESCO, 1969). Tendo tais elementos em consideração, não por acaso as teses em torno da degeneração do mestiço colocaram em xeque o destino dos países amaldiçoados em sua composição social, que seria distinta do requisito do progresso: a pureza racial. Nesse sentido, Conde de Gobineau elenca a miscigenação como causa da derrocada egípcia, perspectiva que assolaria, em breve, o Brasil.

Nesse sentido, os importantes escritos do médico e antropólogo Nina Rodrigues não deixam de refletir as influências desse contexto científico aplicado à realidade social brasileira. Em sua obra As Raças Humanas e a Responsabilidade Penal no Brasil (1894) há a presença da Antropologia Criminal para tecer um vínculo entre tendência à criminalidade e as condições raciais daqueles situados nos estágios mais baixos da evolução. Por sua vez, em Os africanos no Brasil (2008), a preocupação central se dá com a questão da miscigenação brasileira após a abolição da escravatura, não apenas nos seus aspectos físico-biológicos, mas também no que se refere às práticas culturais e às relações sociais.

Dessa maneira, o autor empreende um grande esforço para conhecer a influência dos negros no Brasil e o papel de sua atuação na constituição de um povo brasileiro, por meio de pesquisa das chamadas sobrevivências africanas, a exemplo da língua, religião e manifestações 
culturais e artísticas, temas cuja sistematização e estudos são méritos fundamentais do médico maranhense. Não obstante, Rodrigues mantém a categorização e abordagem de acordo com o instrumental de categorias de raças superiores e raças inferiores, sendo que, a seu ver, a superioridade étnica, moral e intelectual do branco encontrariam entraves na presença do negro e do índio em solo brasileiro. Dessa maneira, o tratamento dado pelo autor decorre de uma visão fatalista e negativa do Brasil, já que o mestiço é caracterizado como uma realidade inferiorizada, um grande problema nacional que mina as possibilidades concretas do progresso civilizatório do país, percurso argumentativo no qual o atraso das artes brasileiras é atribuído à inferioridade das artes entre os negros, assim como a algazarra e barulho que predominam nas festas.

O bom senso mostra que, excetuando-se a mestiçagem física, espiritualmente nos mestiçamos em tudo, não seria de se acreditar que a essa mistura houvesse escapado a linguagem e dele não deva perdurar alguma coisa na massa popular, malgrado a autoridade e o exemplo dos bons mestres, continuamente a se inspirarem nos monumentos escritos do idioma (Ibid., p. 117).

Nesse diagnóstico, juntamente com o panorama intelectual da época, o destino do Brasil e a possibilidade de construção de um verdadeiro Estado-Nação sangravam com o peso negativo e irremediável da história e população nacionais. Biologicamente amaldiçoado, socialmente degenerado, o caminho postulado por Rodrigues residia na eliminação das discrepâncias raciais e da maldição do mestiço.

Essa visão das misérias e ranços que supostamente configuravam a patologia brasileira se expressa também na literatura, em especial na escola naturalista, cuja influência darwinista já foi citada. Em suas características literárias destacam-se elementos como a zoomorfização e a visão do ser humano enquanto produto biológico do meio e da raça, em uma negação da possibilidade de livre arbítrio ou vontade individual. Esses aspectos são perceptíveis na obra O Cortiço (1890).

Eram cinco horas da manhã e o cortiço acordava, abrindo, não os olhos, mas a sua infinidade de portas e janelas alinhadas. Um acordar alegre e farto de quem dormiu de uma assentada, sete horas de chumbo. (...) O rumor crescia, condensando-se; o zunzum de todos os dias acentuava-se; já se não destacavam vozes dispersas, mas um só ruído compacto que enchia todo o cortiço. Começavam a fazer compras na venda; ensarilhavam-se discussões e rezingas; ouviam-se gargalhadas e pragas; já se não falava, gritava-se. Sentiase naquela fermentação sangüínea, naquela gula viçosa de plantas rasteiras que mergulham os pés vigorosos na lama preta e nutriente da vida, o prazer animal de existir, a triunfante satisfação de respirar sobre a terra (AZEVEDO, 1974, p. 28). 
Nesse clássico da literatura nacional, Aluísio Azevedo narra a história de Jerônimo, português que inicialmente se define por sua alta capacidade de trabalho e disciplina, porém acaba por ser corrompido a partir de seu relacionamento com a mulata Rita Baiana. Na história também há a figura de Bertoleza, mulher escravizada, criada e amante do personagem e protagonista João Romão, sendo que, se Rita Baiana se mostra como asseada, agradável, preguiçosa e, principalmente, sensual, Bertoleza é completamente animalizada e destituída de qualidades e falas. Acerca da sensualidade que reveste a noção da mulata brasileira, “(...) ninguém como a Rita, só ela, só aquele demônio, tinha o mágico segredo daqueles movimentos de cobra amaldiçoada; aqueles requebros que não podiam ser sem o cheiro que a mulata soltava de si e sem aquela voz doce, quebrada, harmoniosa, arrogante, meiga e suplicante" (Ibidem, p. 57). Assim:

Cercavam-na homens, mulheres e crianças; todos queriam novas dela. Não vinha em traje de domingo; trazia casaquinho branco, uma saia que lhe deixava ver o pé sem meia num chinelo de polimento com enfeites de marroquim de diversas cores. No seu farto cabelo, crespo e reluzente, puxado sobre a nuca, havia um molho de manjericão e um pedaço de baunilha espetado por um gancho. E toda ela respirava o asseio das brasileiras e um odor sensual de trevos e plantas aromáticas. Irrequieta, saracoteando o atrevido e rijo quadril baiano, respondia para a direita e para a esquerda, pondo à mostra um fio de dentes claros e brilhantes que enriqueciam a sua fisionomia com um realce fascinador. Acudiu quase todo o cortiço para recebê-la. Choveram abraços e as chufas do bom acolhimento (Ibidem, p. 45).

Dessa forma, a obra em questão pode ser utilizada como um exímio retrato dos estereótipos e imaginários presentes na concepção de negros e mulatos no Brasil, e explicitam de certa forma o caráter degenerador atribuído ao contato das raças inferiores com as raças superiores, a partir da compreensão das teorias racialistas do século XIX. Por fim, resta o questionamento de Ki-Zerbo: “A preeminência histórica da cultura sobre a biologia é evidente desde a aparição do Homo no planeta. Quando irá tal evidência impor-se aos espíritos?” (KIZERBO, 2010, p. 292).

\section{Do antagonismo à unificação: $\mathrm{O}$ Brasil a partir da miscigenação}

Publicada em 1933, Casa Grande \& Senzala impactou profundamente a intelectualidade e a política brasileira por representar uma operação que permitiu o enfrentamento da questão nacional em novos termos. Consensualmente considerada a mais significativa das obras de Gilberto Freyre, Casa Grande \& Senzala alcança esse posto na 
literatura do pensamento social brasileiro por estar calcada no novo instrumental teórico analítico do culturalismo estadunidense, encabeçado por Franz Boas.

Isto posto, vale salientar que foi esta aproximação de Freyre junto à antropologia estadunidense a determinante responsável para o autor pensar a separação entre as noções de raça e de cultura, conferindo uma supremacia do elemento cultural na análise da vida social. Por meio das contribuições teóricas de Franz Boas (referência), a diversidade cultural se torna elemento a ser valorizado, o que cria certas condições para que "o diferente" fosse alvo de reflexão e pesquisa dentro do paradigma científico estabelecido no Ocidente. Com amparo nesse horizonte conceitual-analítico, Freyre conseguiu se distanciar dos pensadores do século XIX, redefinindo a ideia de mestiçagem e, por conseguinte, redefinindo também a concepção do caráter nacional brasileiro.

Ao desvincular a raça, de certa forma, do universo histórico e pseudocientífico das associações preconceituosas e deterministas, Freyre atendeu - involuntariamente ou não - uma fundamental demanda política. Converter a mestiçagem em um elemento positivo e alegar que o distanciamento entre europeus, africanos e indígenas é fictício significou afirmar que a superioridade e inferioridade entre as etnias não existe de maneira rígida, já que o intercâmbio cultural produz a mestiçagem e miscigenação. Assim, o autor descreve, inclusive, o português colonizador e/ou dominador como alguém despido de uma pretensa pureza, na medida em que possui suas origens milenares baseadas nas misturas com diversos povos. Assim sendo, o novo discurso intelectual de Freyre dá base para a interpretação de que o Brasil seria, em realidade, fruto de trocas culturais de origem milenar e provenientes da globalização, assim como apontado pelo autor no princípio do capítulo quatro do livro:

Todo brasileiro, mesmo o alvo, de cabelo louro, traz na alma, quando não na alma e no corpo - há muita gente de jenipapo ou mancha mongólica pelo Brasil - a sombra, ou, pelo menos, a pinta, do indígena ou do negro. No litoral, do Maranhão ao Rio Grande do Sul, e em Minas Gerais, principalmente a do negro. A influência direta, ou vaga e remota, do Africano (FREYRE, 2006, p. 367).

Por isso, Casa Grande \& Senzala é uma obra canônica e inovadora para a compreensão da formação social brasileira. Com ênfase no caráter sexual da relação entre os senhores das casas grandes e as negras das senzalas, a obra tem por objetivo a análise e o estudo de uma sociedade etnicamente integrada, na qual a miscigenação é tida como elemento responsável pelo apaziguamento das discrepâncias e das diferenças étnicas no período de formação do país. Com efeito, as teorias racialistas assentadas nas categorias rígidas de superioridade e inferioridade racial não possuíam concretude e apenas justificavam o racismo. A partir do 
critério da miscigenação, o pensamento de Gilberto Freyre funciona como aparato de explicação e entendimento da complexa sociedade brasileira, dando, por conseguinte, as bases da possibilidade do advento do Estado-Nação.

Todavia, devido ao fato de as teorias de superioridade e inferioridade racial já estarem muito arraigadas no Brasil, cria-se uma forte contradição para pensar um projeto de EstadoNação modernizador, atrelado ao desenvolvimento econômico e político capitalista autônomo, ainda mantendo teorias e estratégias políticas embasadas nas ideias de "superioridade" e “inferioridade" com respeito ao indígena e ao negro; "A generalização de que o homem é escuro ou preto nas regiões quentes, róseo ou alvo no hemisfério norte" (FREYRE, 2006, p. 375), ou a utilização de medidas e observações anatômicas de craniometria para supostamente comprovar a inferioridade e ignorância das chamadas raças inferiores, dentre tantos outros exemplos abordados por Gilberto Freyre.

Por isso, dá-se ênfase à refutação das teses de inferioridade e superioridade que o autor promove, mostrando assim como a relação entre a casa grande e senzala fomenta a mestiçagem e miscigenação da sociedade brasileira e, simultaneamente, pavimenta o caminho teórico do surgimento do Estado-Nação.

\begin{abstract}
A casa-grande fazia subir da senzala para o serviço mais íntimo e delicado dos senhores uma série de indivíduos - amas de criar, mucamas, irmãos de criação dos meninos brancos. Indivíduos cujo lugar na família ficava sendo não o de escravos, mas o de pessoas de casa. Espécie de parentes pobres nas famílias europeias. Á mesa patriarcal das casas-grandes sentavam-se como se fossem da família numerosos mulatinhos. Crias, Malungos, Moleques de estimação. Alguns saiam de carro com os senhores, acompanhando-os aos passeios como se fossem filhos (FREYRE, 2006, p. 435).
\end{abstract}

Gilberto Freyre, ao colocar todas as etnias em igual grau de importância e ao afirmar que a mestiçagem, ao contrário de atraso, levaria ao progresso, não fornece apenas uma resposta à política, mas também confere uma resposta à antropologia, ao argumentar que a mestiçagem não remete apenas à biologia, mas a uma rica herança cultural.

Em relação à constituição do Estado-Nação brasileiro, outro ponto a ser destacado diz respeito ao momento em que seu olhar se dirige para o interior da casa grande com a finalidade de expressar, por meio dele, o Brasil. Freyre relata as mazelas e a violência que nele se configuram, na medida em que é na casa em que se vivencia a dinâmica empírica do contato entre as diferentes raças e culturas, isto é, é no interior da casa que os opostos culturais estabelecem uma convivência postos no mesmo espaço (FREYRE, 2006). Dessa forma, Freyre constrói uma narrativa que, ao menos em um primeiro plano, se afasta da exclusão que antes era explicitamente colocada pelas teorias racialistas e destaca a necessidade de convivência 
entre os opostos que habitam o mesmo espaço, tendo por eixo o contato sexual entre os mesmos. É importante ressaltar que tais apontamentos não significam que de fato a consolidação do Estado nacional brasileiro é permeada pela igualdade de direitos e posições entre negros e brancos, mas sim que a operação de Freyre permite ao menos conceber a possibilidade de que o Brasil fosse um empreendimento viável mesmo sem o purismo etnocêntrico que era defendido anteriormente. Segundo Freyre, todas as chaves de formação e explicação culturais deveriam ser consideradas ao se pensar um Estado-Nação devidamente modernizado.

A repercussão das ideias contidas em Casa Grande \& Senzala moldou um pensamento nacional baseado na harmonia natural das populações raciais no Brasil. Todavia, com alarde especial às últimas décadas do século XX, foram várias as correntes teóricas que contestaram os aspectos da harmonia das três raças, sustentáculo do pensamento de Gilberto Freyre, e que condicionara a uma ampliação do horizonte da análise sociológica acerca da relação entre modernização e a questão racial no Brasil. Um dos mais notáveis e importantes referenciais teóricos está na célebre obra A integração do Negro na Sociedade de Classes, em que Florestan Fernandes, alicerçado firmemente nos pressupostos marxistas, propugna a tese de que nenhuma instituição chamou para si a responsabilidade de integrar efetivamente o exescravizado no novo sistema de trabalho erigido com a abolição da escravatura. Desse modo, desprovidos de quaisquer meios morais e materiais, os escravos viam-se libertos somente na letra da lei enquanto eram, repentinamente, lançados numa ordem competitiva que os desamparava. Nesse sentido, o pensamento de Florestan Fernandes lança luz para a compreensão de que modernização da sociedade brasileira com a consolidação da sociedade de classes não se deu de maneira homogênea para a toda população (FERNANDES, 1965). Assim o autor caracteriza o "déficit negro", expressão das causas psicossociais e/ou socioculturais que colocam a parcela da população negra em situação de desvantagem quando em competição com a população branca, sobretudo o estrangeiro do contexto da Industrialização no primeiro quartel do século XX:

Os negros e os mulatos ficaram à margem ou se viram excluídos da prosperidade geral, bem como de seus proveitos políticos, porque não tinham condições para entrar nesse jogo e sustentar as suas regras. Em consequência, viveram dentro da cidade, mas não progrediram com ela e através dela (FERNANDES, 1965, p. 71).

Depreende-se deste modo que a produção teórica de Fernandes cumpriu um papel fundamental ao descortinar os pressupostos idílicos do passado escravista brasileiro. Ademais, o sociólogo aprofunda sua criticidade ao comprovar que, mesmo após o fim do modo de 
produção escravista, os negros continuaram marginalizados e sem condições objetivas de ascender socialmente na sociedade de classes que então se constituía no país.

Sobre essa perspectiva, Carolina Maria de Jesus, na sua obra Quarto de despejo, publicada em 1960, assume grande relevância no debate intelectual, na medida em que exibe um discurso crítico e um profundo questionamento à modernidade precária que coloca o negro numa experiência marginalizada e subalterna ao longo dos anos 1940 e 1950. Em seus diversos escritos autobiográficos, a autora expõe seus sentimentos e percepções sobre a realidade que a cercava, com a forte predominância de relatos que expressam a forma com a qual a violência social contra a população negra era naturalizada no cotidiano brasileiro. Descrevendo comportamentos, valores, os hábitos e costumes da época, Carolina de Jesus permite pensar a complexidade da formação social brasileira, principalmente no que tange a desigualdade socioeconômica, a persistência de relações de dependência pessoal e as barreiras que impediam o ingresso dos negros à esfera dos direitos. Conforme corrobora tal relato:

[...] Estou residindo na favela. Mas se Deus me ajudar hei de mudar daqui. Espero que os políticos estingue as favelas. Há os que prevalecem do meio em que vive, demonstram valentia para intimidar os fracos. Há casa que tem cinco filhos e velha é quem anda o dia inteiro pedindo esmola. Há as mulheres que os esposos adoecem e elas no penado da enfermidade mantem o lar.

Sob forma de testemunho pessoal, os escritos carolinianos, fundamentalmente na obra Quarto de despejo, carregam em si as contradições da sociedade brasileira, colocando em foco os elementos do atraso que não foram equacionados com o movimento modernizador realizado a partir do marco histórico dos anos 30.

\section{Considerações finais}

O contexto de construção de um Estado brasileiro inserido no projeto iluminista de uma sociedade racional está presente em grande parte do processo histórico brasileiro. A incessante tentativa de inserção do Brasil no mercado internacional, expressa de forma mais notável na consolidação da República, via modernização tecnológica e alcance de um ideal de modernidade, não chega a resolver completamente o panorama legado do passado colonial: uma população analfabeta, de base escravocrata e dependente de uma elite patrimonialista.

O cenário do pensamento social brasileiro pós década de 20 procura consolidar-se a partir da inovação cultural e das práticas científicas. A busca por uma identidade nacional, no entanto, não perde seu protagonismo. A característica da política brasileira de importação de 
modelos como caminho para a modernidade também recai no aporte científico; as teorias cientificistas influenciaram estruturalmente os intelectuais e a sociedade da época. É dessa forma que o ideal de branqueamento e, portanto, não só o ocultamento, mas rebaixamento de toda influência da cultura africana encontrou sua base nas teorias raciais, que com a inscrição da inferioridade nos corpos negros, naturalizam a desigualdade. A partir daí, criam-se barreiras que excluem a possibilidade de mudança do horizonte social. As teorias cientificistas, pois, serviram como base de sustentação e legitimidade da posição e status da elite dominante do país.

Os estudos realizados no século XX ainda encontram comprovação empírica na atualidade, quando a Comissão de Combate à Intolerância Religiosa do Rio de Janeiro (CCIR), realiza uma pesquisa na qual cerca de $70 \%$ dos casos registrados, entre 2012 e 2015, referemse às religiões de matrizes africanas. Arthur Ramos (1940), influente pensador do séc. XX, já colocava o combate da religiosidade como essencial para conquista da autonomia negra prometida com o advento da modernidade, tendo em vista que o universo da crença estrutura todas as relações sociais de um povo; é necessário, pois, introduzir novos valores culturais e sociais a essa população considerada pré-lógica.

É diante desse quadro que o debate sobre o alcance de uma modernidade no Brasil, e, portanto, da consolidação de uma cidadania, ainda se faz crucial. A formação de cidadãos plenos, isto é, que envolva a garantia dos direitos civis, sociais e políticos, é colocada em xeque a partir do momento que nos deparamos com índices absurdos, podendo-se dizer até bárbaros, de violência, desemprego, escolaridade, saneamento e, por conseguinte, das diversas formas de desigualdades presentes no contexto histórico brasileiro.

\section{REFERÊNCIAS}

AZEVEDO, Aluísio. O Cortiço. São Paulo: Editora Ática, 1974.

BOAS, Franz. Antropologia cultural. 6ª ed. Rio de Janeiro: Jorge Zahar Ed., 2010.

FERNADES, Florestan. A integração do negro na sociedade de classes: o legado da 'raça branca'. São Paulo: Dominus/Editora da Universidade de São Paulo, 1965.

FREYRE, Gilberto. Casa-grande e senzala: formação brasileira sob o regime da economia patriarcal. São Paulo: Global, 2006.

JESUS, Carolina Maria de. Quarto de despejo: diário de uma favelada. $6^{\mathrm{a}}$ Ed. São Paulo: Editora Paulo de Azevedo, 1960. 
KI-ZERBO, Joseph. Teorias relativas às "raças" e história da África. In: História Geral da África: metodologia e pré-história da África. Brasília: UNESCO, p. 283-293, 2010.

NOGUEIRA, Marco Aurélio. Os Anos Trinta. Revista de Ciências Sociais, Unesp. Perspectivas, vol. 11, p. 93-99, 1988.

OLIVEIRA, Ricardo de. Euclides da Cunha, Os Sertões e a invenção de um Brasil profundo. Revista Brasileira de História, v.22, n. 44, p. 511-537. São Paulo, 2002.

PUFF, Jefferson. Por que as Religiões de Matriz Africana são o Principal Alvo de Intolerância no Brasil? BBC. Rio de Janeiro, 21 jan. 2016. Disponível em:

http://www.bbc.com/portuguese/noticias/2016/01/160120_intolerancia_religioes_africanas_j p_rm. Acesso em: 25 nov. 2017.

RAMOS, Arthur. O negro brasileiro: etnografia religiosa. $2^{a}$ ed. São Paulo: Companhia Editora Nacional, 1940.

RODRIGUES, Raymundo Nina. Os africanos no Brasil. São Paulo: Madras, 2008.

\section{Como referenciar este artigo}

SILVA, Laura Gabrieli Pereira da; OLIVEIRA, Fabrício Henrique de. A construção de uma nação: entre a conservação e a mudança no século XX brasileiro. Rev. Sem Aspas, Araraquara, v.7, n.2, p. 170-181, jul./dez., 2018. ISSN: 2358-4238. DOI: 10.29373/sas.v7i2.11897

Submetido em: $15 / 11 / 2018$

Aprovado em: 08/01/2019 